\title{
DEVELOPMENTS IN QUANTITATIVE ORGANIC ULTRAMICRO ELEMENTARY ANALYSIS
}

\author{
W. J. KIRSTEN \\ Department of Chemistry, Agricultural College of Sweden S-750 07, \\ Uppsala, Sweden
}

\begin{abstract}
Numerous principles for the mineralization of samples and for the measurement of the elements have been tricd since the days of Liebig, Dumas, Dennstedt and Pregl. Attempts to develop accurate and reliable ultramicro methods have been successful only in recent years.

Almost absolutely quantitative recovery of the analyte from the mineralization process, freedom from risk of contamination, and very high sensitivity and specificity of the measuring method are the main requirements for the usefulness of a procedure for ultramicroanalysis.

A number of excellent available methods are described and discussed with regard to these requirements.

The most difficult problem is the quantification of hygroscopic and other difficult samples prior to analysis. This problem and a few solutions to different cases are discussed.
\end{abstract}

For the quantitative determination of an element in a sample, the sample must be destroyed and the element isolated as a homogeneous, easily measurable compound. The most common methods for the destruction are heating in a flow of gas, which liberates the elements to be measured as volatile compounds; stationary combustion in a closed, oxygen-filled container, in which the combustion products can be absorbed and measured; and decomposition in hot oxidizing acids or alkalis, in which the analytes remain dissolved.

\section{METHODS USING DECOMPOSITION IN A GAS FLOW}

\section{Carbon, hydrogen, nitrogen}

A good example of the gas flow decomposition method is shown in Figure 1. This method which was described by Belcher et al. ${ }^{1}$ is adapted to deal with samples of between 5 and $50 \mu \mathrm{g}$. It was the first successful method for the determination of carbon and hydrogen with samples of below $100 \mu \mathrm{g}$.

When carbon, hydrogen and nitrogen are to be determined simultaneously the decomposition of the sample can be so arranged that carbon dioxide, hydrogen and nitrogen are the final products. They are all gaseous at low concentration and determination by gas chromatography has been attempted by several authors on the micro scale. Again Belcher and his co-workers ${ }^{2}$ 
were the first to work out a method which made possible the successful analysis of samples of between 40 and $80 \mu \mathrm{g}$. With samples of acetanilide, they obtained standard deviations of 0.31 per cent for carbon, 0.28 per cent for hydrogen and 0.11 per cent for nitrogen. However, the chromatographic properties of carbon dioxide, water and nitrogen are too unlike each other to allow a simple separation on a column, and complicated arrangements had to be made.

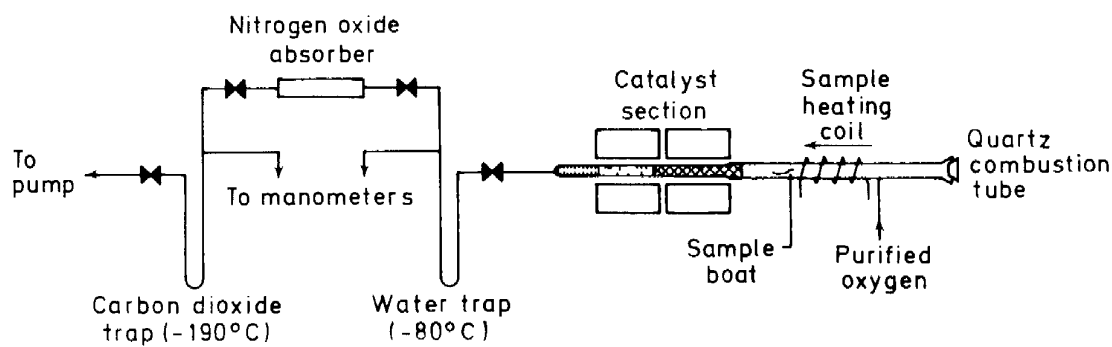

Figure 1. Manometric method for carbon, hydrogen and nitrogen ${ }^{1}$. The sample is burned in a flow of oxygen over the catalyst in the combustion tube. The gas passes through the water trap, where the water is frozen out, through the nitrogen oxide absorber into the carbon dioxide trap, where the carbon dioxide is frozen out. The traps are then evacuated and. after warming them, the gaseous water and carbon dioxide are measured in specially designed manumeters.

Walisch ${ }^{3}$ described a decimilligramme apparatus which was commercially produced by Technicon. Figure 2 shows an apparatus of this type which was modified in our laboratory, and which we have used for samples down to $50 \mu \mathrm{g}$. We are convinced that after a few further minor refinements, even smaller samples can be analysed according to this principle.

Working with this method we found that one of the most important factors in the accurate measurement of low concentrations of gas with a thermal conductivity detector, is the absolute stability of the gas flow. Changes of the flow rate influence the results in three ways. Firstly, the length of time the gas dwells in the detector cell is changed. Secondly, the rate of heat conduction from the wire is changed, and the third, very important effect, is that the composition of the carrier gas is changed. Atmospheric nitrogen diffuses into the apparatus through all-plastic or rubber tubing connections and through ground joints. This diffusion takes place at a constant rate, and when the carrier gas passes through the tubing at a constant rate its content of diffused nitrogen reaches a steady state. When the rate of flow increases the nitrogen content diminishes, and it becomes higher when the rate decreases. This influence can easily be demonstrated by pinching off the flow of helium at the tank for about thirty seconds. When it is turned on again, the integrator will register as the waves of nitrogen-containing helium from the tubing, pass through the detector.

We have, therefore, taken scrupulous precautions to stabilize the flow, not only in the apparatus itself, but also in the line from the tank to the apparatus, and we have eliminated most plastic tubings and connections in the setup. A series of results is shown in Table $1^{3}$. 
A very similar apparatus with the same detector and integrator arrangement described by Walisch and Marks ${ }^{4}$ is used for the determination of oxygen. The modified apparatus is shown in Figure 3. It works very well with samples down to $50 \mu \mathrm{g}$.

We have found it very convenient to mount the furnace setups for C,H,N and for oxygen determination on a turn-table, so that the same detector and integrator assembly can be used for both kinds of determination. The output of analyses from the equipment is about 25-30 runs per working day. It is therefore not necessary in our laboratory to determine $\mathrm{C}, \mathrm{H}, \mathrm{N}$ and oxygen every day, but the methods can be used alternately with the same electronic equipment.

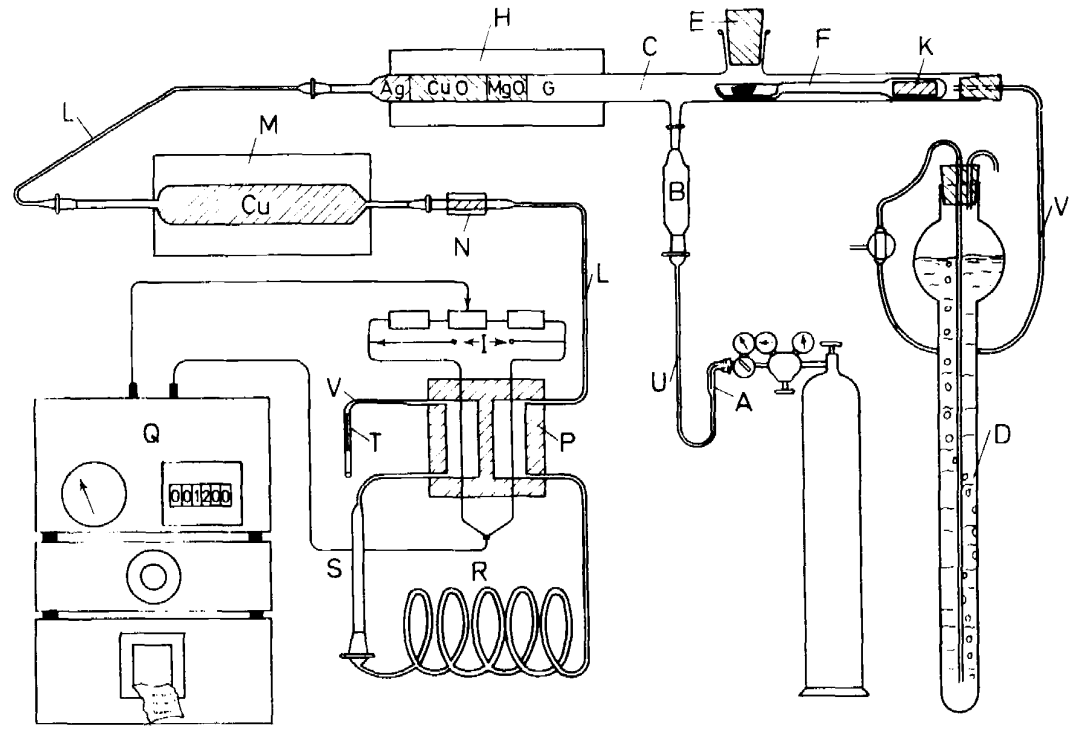

Figure 2. Modified Walisch-Technicon apparatus for carbon, hydrogen and nitrogen ${ }^{3}$. A mixlure of helium with 3 per cent of oxygen is passed from the tank through the drying tube B into the combustion tube C. A part of the gas passes to the right and out through the cylinder with water $D$, which keeps the pressure constant in the apparatus. The other part passes to the left through the apparatus. The sample, in a platinum boat, is placed in the quartz spoon $F$ through opening E. The spoon is quickly pushed into the combustion chamber $\mathrm{G}, 1070^{\circ} \mathrm{C}$, with the magnet $\mathrm{K}$. The sample is burned. Combustion products of halogens, sulphur, phosphorus, etc. are retained in the tube filling. Alkali carbonates are decomposed at the high temperature of chamber $\mathrm{G}$ and most metals are retained as oxides in the boat. Carbon dioxide, water, nitrogen and nitrogen oxides from the sample pass through the reduction furnace with metallic copper $M$, where the excess of oxygen in the combustion gas is absorbed and the nitrogen oxides are reduced to elemental nitrogen. The water is then absorbed in the small layer of silica gel in the cold furnace $\mathrm{N}$, and the remaining carbon dioxide and nitrogen passes into the right cell of the catharometer $P$, which gives its signal to the electronic setup $Q$ where it is intcgrated, and printed out. The figure represents the sum $\mathrm{CO}_{2}+\mathrm{N}_{2}$. The gas passes into the delay coil of copper $\mathrm{R}$, and through the absorption tube $\mathrm{S}$ where the carbon dioxide is absorbed. The remaining gas, which now only contains the nitrogen, passes through the left cell of the catharometer $P$ and out through capillary T. The signal from the catharometer is again integrated and printed out. It represents $N_{2}$. Finally the silica gel in furnace $\mathrm{N}$ is heated. The water is liberated, passes into the catharometer, and is measured in the same manner. The sample's content of carbon, hydrogen and nitrogen can easily be calculated from the figures obtained. $I$ is the bridge feeding voltage; $L$ is silver tubing, inner diameter $0.4 \mathrm{~mm}$; $U$ stainless steel capillary, and $\mathrm{V}$ is Tygon tubing. 
W. J. KIRSTEN

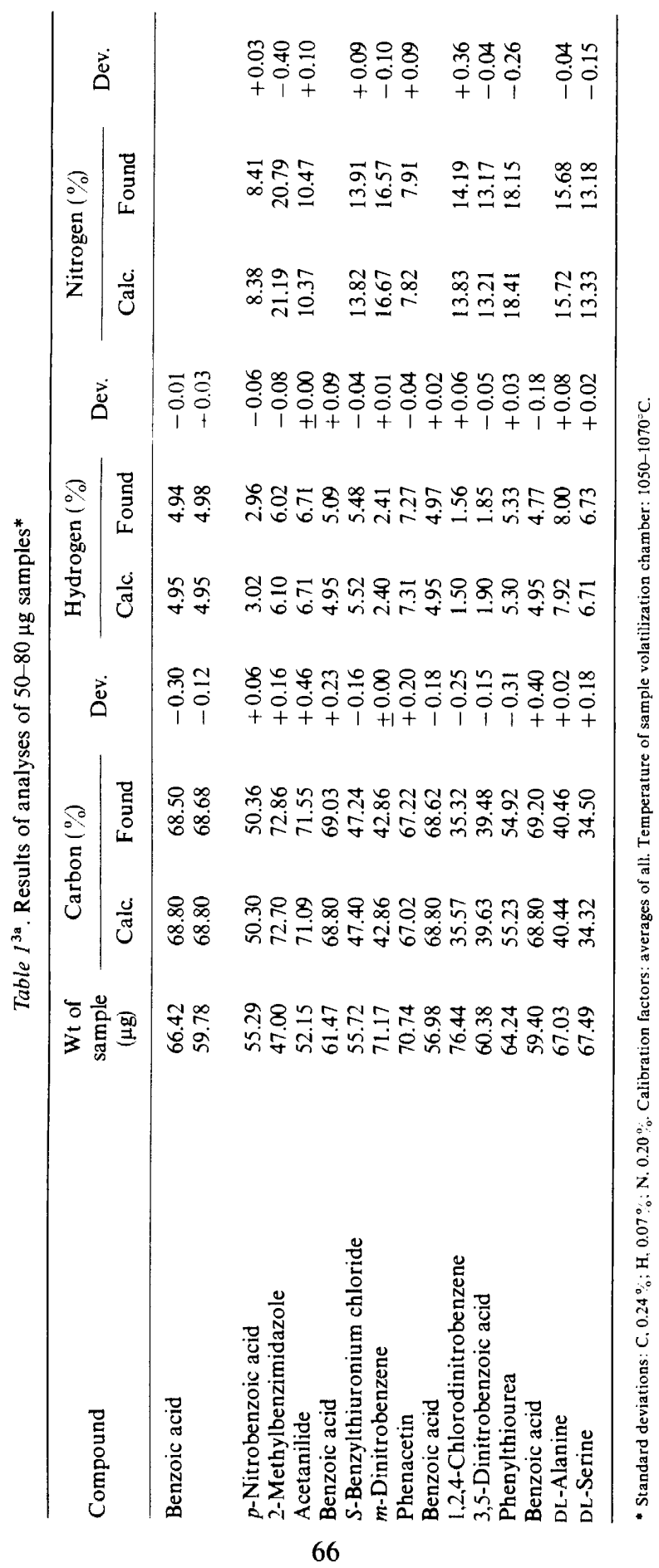




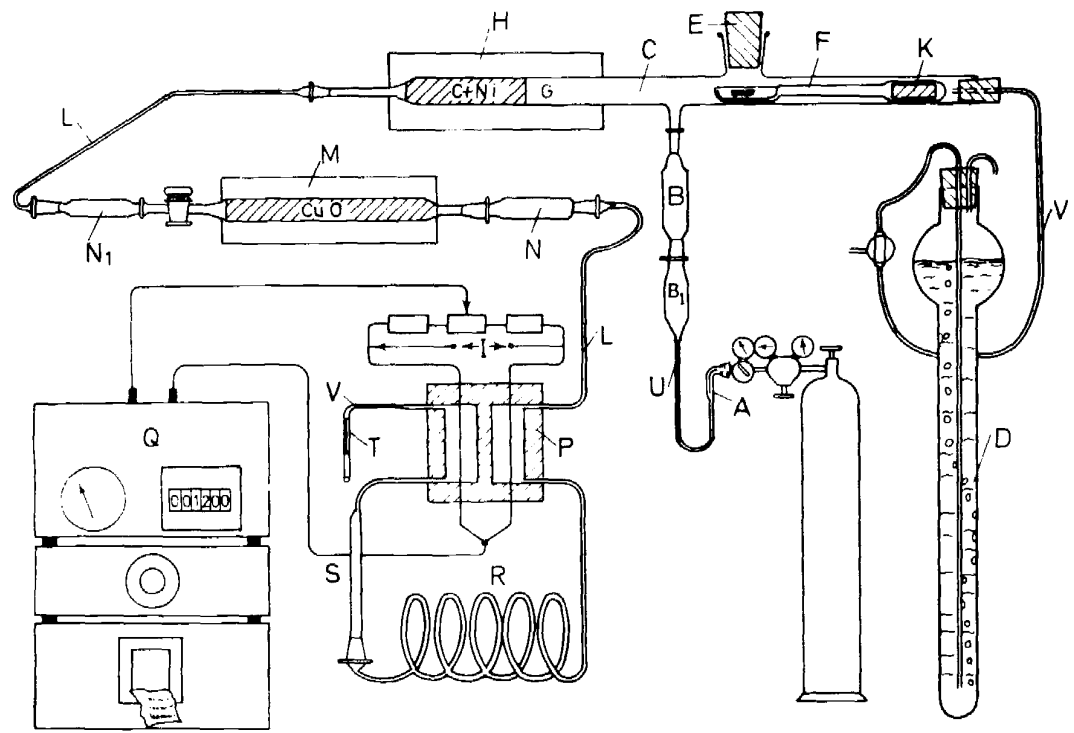

Figure 3. Modified Walisch and Marks-Technicon apparatus for oxygen ${ }^{4}$. Lettering as in Figure 2. The platinum boat with the sample is placed in the quartz spoon $\mathrm{F}$ in a flow of helium with 1 per cent of hydrogen. It is pushed into the pyrolysis chamber $\mathrm{G}$ of furnace $\mathrm{H}$. The gases formed pass through a layer of nickelized carbon at $970^{\circ} \mathrm{C}$. Carbon monoxide is formed from all of the oxygen of the sample. Interfering substances are retained in tube $\mathrm{N}_{1}$ and carbon monoxide and hydrogen are oxidized to carbon dioxide and water in the furnace $\mathrm{M}$ at $250 \mathrm{C}$. The water is retained in tube $\mathbf{N}$. Now we have exactly the same gits mixture as in the determination of $\mathrm{C}, \mathrm{H}, \mathrm{N}$ described above: helium, carbon dioxide, and most of the nitrogen of the sample. The measurement is made in the same manner. First the sum of carbon dioxide and nitrogen is measured in the right chamber of the catharometer, then the carbon dioxide is absorbed and the nitrogen measured in the left chamber. The difference represents the oxygen of the sample. The figure for nitrogen is usually low, but it can give an indication of the nitrogen content of the sample.

\section{Sulphur, halogens}

In tube combustion, sulphur is burned to $\mathrm{SO}_{2}$ and $\mathrm{SO}_{3}$ and halogens form hydrogen halides and free halogens. Some of these compounds are readily bound to any basic spots on the tube walls and are thus withdrawn from the determination. This cause of error is less important in microanalysis, but is substantial in ultramicroanalysis. Either the combustion tube must be cleaned very frequently, or the adsorbed compounds must be desorbed somehow.

If the samples contain alkaline ashes these will also retain sulphur and halogen. The alkali must, therefore, be neutralized. A number of compounds have been described for this purpose. We have investigated vanadium pentoxide, tungsten trioxide, phosphorus pentoxide, metaphosphoric acid and orthophosphoric acid. The only compound which gave a reliable decomposition of alkali sulphates and halides in whatever form they were used, was orthophosphoric acid. Orthophosphoric acid is liquid and wets the sample well even before the heating. It not only expels sulphur and halogen from the ashes of the sample, but desorbs them also from alkaline spots 


\section{W. J. KIRSTEN}

on the walls of the vessels. Numerous analyses can therefore be carried out without the troublesome necessity of cleaning the vessels again and again. Of course the phosphoric acid must be compatible with the subsequent measuring method.

A method for the ultramicro determination of sulphur by combustion and subsequent hydrogenation ${ }^{5}$, is shown in Figure 4. The reaction tube is completely empty. The temperatures of the furnaces are important. When the temperature of the combustion furnaces is higher than $700^{\circ} \mathrm{C}$ small sulphur blanks are obtained, up to about $0.1 \mu \mathrm{g}$ per analysis at $900^{\circ} \mathrm{C}$. At this temperature a slight volatilization of silica from the combustion tube takes place. It is therefore possible that the sulphur originates from the silica, and that higher temperatures could be used with sulphur-free silica tubing. We are now investigating this question.

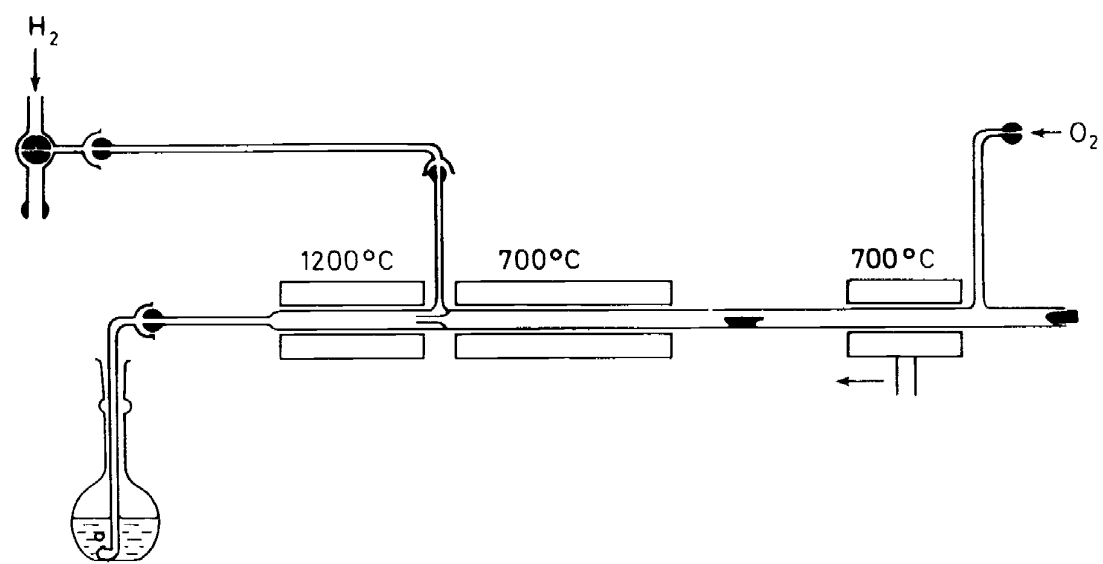

Fiqure 4. Combustion hydrogenation assembly for sulphur ${ }^{5}$. The sample, which has been moistened with $5 \mu \mathrm{l}$ of 10 per cent orthophosphoric acid, is burned in a flow of oxygen at $700^{\circ} \mathrm{C}$. The combustion gases pass through a capillary into a flow of an excess of hydrogen at $1200^{\circ} \mathrm{C}$. The hydrogen sulphide formed is absorbed and reacted to ethylene blue. In determinations of extreme sensitivity a $1 \mathrm{ml}$ absorption flask is used, and water and other reaction products are taken out with a small scrubber before the absorption flask.

In the method used in our laboratory the hydrogen sulphide formed is absorbed in zinc acetate and reacted to ethylene blue, using a modification of the method described by Rees and co-workers ${ }^{6} .0 .01 \mu \mathrm{g}$ of sulphur can be detected, and $0.1 \mu \mathrm{g}$ can be measured with satisfactory accuracy. A great advantage is the remarkable specificity of the colour reaction. The molecules of methylene blue and of ethylene blue are associated with each other in water solution. Therefore, in the original procedures the calibration curve does not follow Beer's law. We found that this association can be eliminated by the addition of pyridine, which probably associates with the colour molecules and thus separates them, or by addition of dodecyl benzene sulphonate, which forms water-soluble ion pairs with them ${ }^{7}$. Beer's law is now also obeyed in quite concentrated water solutions of the colour. Molar absorbance for sulphur is 69.000 .

Tölg $^{8}$ has described a very ingenious apparatus for the decomposition 
of ultramicro samples in a gas flow. It is shown in Figure 5. After the decomposition the reaction products can be collected in the highly efficient absorption and titration vessel (Figure 6) or they can be subjected to further reactions before the absorption, as shown in Figure 7.

With this apparatus, or modifications of it, Tölg and his co-workers have been able to determine carbon in samples of between 4 and $15 \mu \mathrm{g}^{10}$, and in addition they have determined amounts of hydrogen below $2 \mu \mathrm{g}^{11}$, sulphur down to $3.5 \mathrm{ng}^{8}$, and chlorine, bromine and iodine between 0.5 and $5 \mu \mathrm{g}^{12-14}$. They have used bipotentiometric titration for the measurement of hydrogen sulphide, formed in the determination of hydrogen and of sulphur, and also for chloride, formed in the decomposition of chlorine compounds. Carbon dioxide is determined by back-titration of barium after the precipitation of the carbon dioxide with an excess of barium.

When the sample to be analysed is decomposed in a flow of gas, the measurement can be made according to two principles. The reaction products can be collected in a vessel, and the measurement of the whole batch be made after the collection. We can call this the 'batch principle'. The other is the 'dynamic principle', in which the reaction products are measured immediately as they come streaming out from the reaction vessel, and their concentration is recorded.

In ultramicroanalysis blanks from reagents or vessels are a serious cause of error. When these factors can be kept minimal and constant, the hatch principle of measurement is quite advantageous, since the largest possible quantity of material is measured in one operation. This gives the least possible measuring error. However, the dynamic method gives us a possibility of control and supervision of the blank errors which is extremely useful: the signal from a catharometer or the current from a coulometer can be fed into a recorder. Even the rate of movement of a syringe burette can be transformed into an electric signal and recorded. When the blank is constant a straight base-line results. The reaction products from the sample will then give a peak on this base-line which can be integrated. In this manner an automatic compensation for the blank is obtained, and, at the same time the whole measurement is kept under good control. Any change of the blank will immediately show up as a shift of the base-line, and if the blank drifts uniformly, such drift will not interfere with the measurement of the peak. It is very difficult to obtain such favourable control of the analysis when batch measurement is used. Separate blanks must be run before and after the analysis. Even then our knowledge of the influence of the blank upon the result is incomplete. The run tells us that the blank has shifted, but does not tell us whether there has been a slow drift or a sudden change, and it does not tell us whether the change has taken place before, after or during the analysis of the sample. Thus the dynamic measuring method makes it possible to obtain reasonably good results even in the many cases where the conditions of the analysis are not very favourable-which quite often happens in ultramicroanalysis. The matter is illustrated in Figure 8.

Apparatus for the dynamic type of ultramicro determination is the Dohrmann microcoulometer, Infotronics, Mountain View, California, USA $^{15,16}$, and a potentiometric apparatus for chlorine recently described by Krijgsman and Griepink ${ }^{17}$. 


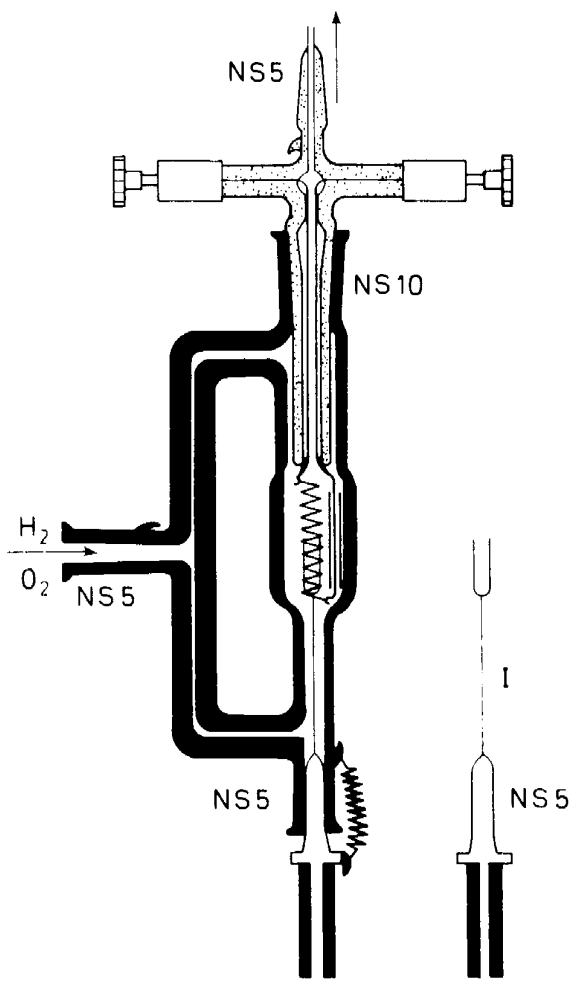

Figure 5. Apparatus for decomposition of samples according to Tölg ${ }^{8}$. The vessel shown by the heavy outline is made of quartz. A tube of resistant glass with conductors for the electric current which heats the spiral of platinum -rhodium wire is introduced and held by the joint NS 10 . The sample is placed into the container on top of the rod on joint NS 5, inset I, and the rod is inserted from the bottom into the apparatus in such a manner that the sample is situated within the heating spiral. The gas for the decomposition passes into the apparatus from the left side. The spiral is now heated and the sample is burned or hydrogenated. As the gas passes into the combustion chamber from both above and below, the reaction products cannot come into contact with joints, but pass right up through the capillary and through the upper joint NS 5 into the absorption chamber, where they can be titrated or measured in another way. 

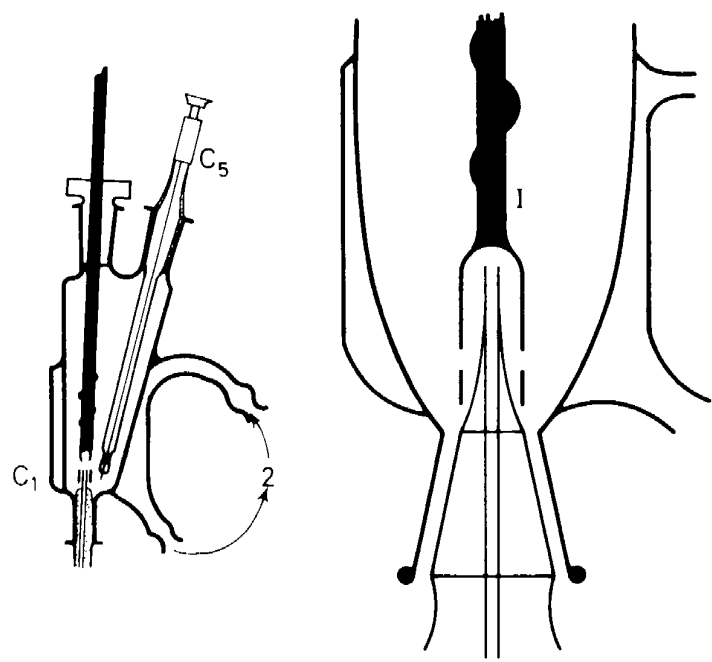

Figure 6. Absorption and titration chamber according to $\mathrm{Tölg}^{9} . \mathrm{C}_{1}$ is the chamber which is placed upon the decomposition vessel, Figure 5. It can be cooled through connections 2 . A complete absorption of the decomposition products is promoted through the 'bell agitator', which is shown enlarged in inset I. It rotates quickly and works like a centrifugal pump. Solution passes into the bell from below and is expelled through the holes together with the reaction gases, which are strongly whipped and dispersed as they pass through. $\mathrm{C}_{5}$ is the electrode set for bipotentiometric titration of halogens with silver nitrate.

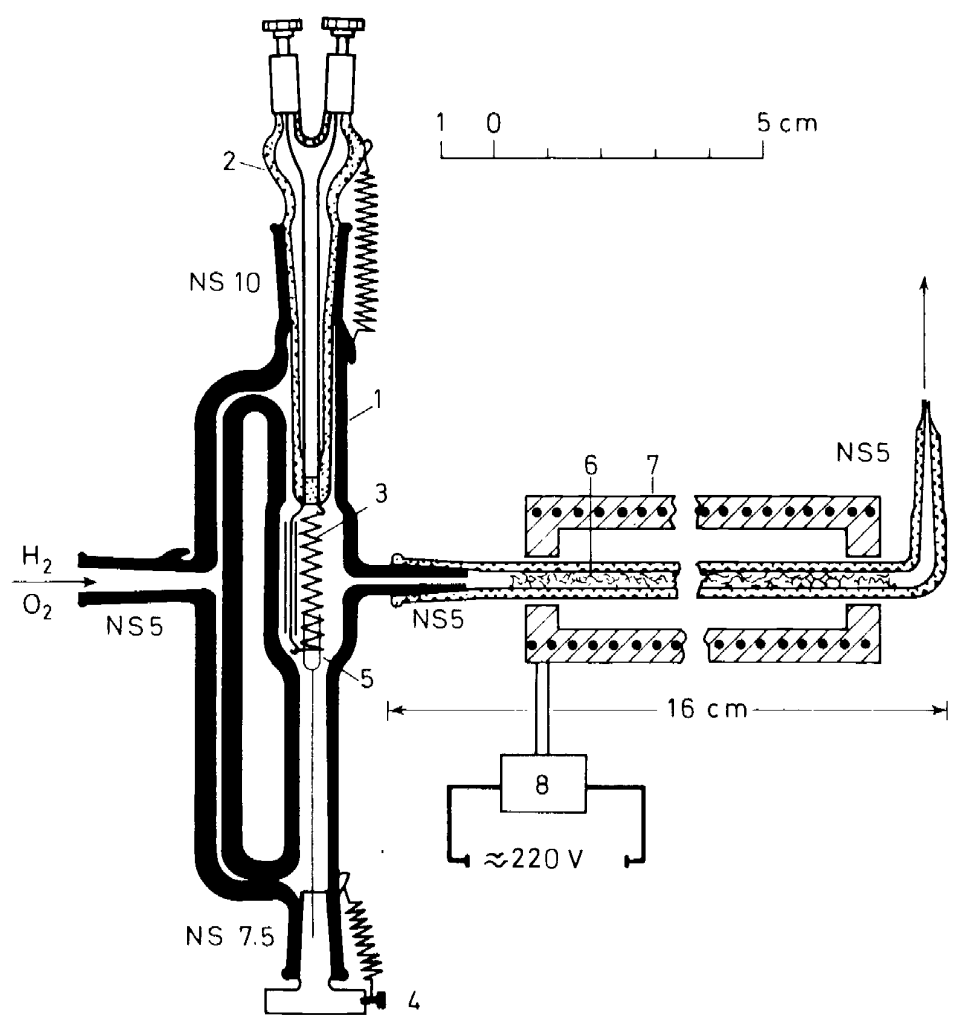

Figure 7. Decomposition apparatus according to Tölg, with contact tube connected ${ }^{8}$. Reaction products can then be absorbed in an absorption vessel placed upon the right joint ${ }^{9}$. 6 , catalyst ; 7, heating furnace; other details as in Figure 6. 
The dynamic measurement is quite common in gas chromatography. In recent years the electronic integrating methods have been improved to a high degree of perfection. The Dohrmann coulometric detector and other element-selective detectors are quite frequently used for trace determinations of elements. When all the experience concerning purity of reagents, adsorption and contamination through walls of vessels, contamination and losses

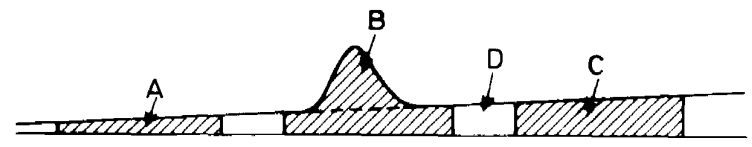

Figure 8. Batch measuring method versus dynamic measuring method when blank is drifting. The three shadowed areas illustrate three runs with the batch method, $\mathrm{A}=$ first blank run, $4 \mathrm{~cm}^{2} ; \mathrm{B}=$ analysis, $15.5 \mathrm{~cm}^{2}$ and $\mathrm{C}=$ second blank run, $12 \mathrm{~cm}^{2}$. The result of the analysis is obtained by subtracting the average of the two blank runs from the result of the analysis. It gives $7.5 \mathrm{~cm}^{2}$. When the measurement is made with the dynamic method only the line $\mathrm{D}$ is recorded. It is sufficient to run the analysis $B$. The lengths of base-line before and after the peak are sufficient to allow an accurate measurement of the peak area. $7.5 \mathrm{~cm}^{2}$.

through joints, etc., which has been gained in classical ultramicroanalysis, is incorporated also in connection with these electronic methods, this will probably lead to further considerable progress in ultramicro elementary analysis, and maybe also in gas chromatographic and other methods of trace analysis.

\section{FLASK COMBUSTION METHODS}

\section{Sulphur, halogens, phosphorus, arsenic, selenium}

Belcher and his school ${ }^{18-20}$ have elaborated flask combustion methods for the determination of fluorine, chlorine, bromine and iodine with samples of between 30 and $80 \mu \mathrm{g}$. They measure the fluorine spectrophotometrically as the blue complex of lanthanealizarine; they titrate the chlorine with mercury using diphenyl carbazone as indicator, and they oxidize bromine and iodine respectively to bromate and iodate respectively, and then titrate these by iodimetry. They have also worked out methods for the determination of $10-30 \mu \mathrm{g}$ of sulphur by titration of the excess of barium after precipitation of the sulphate formed ${ }^{21}$. Phosphorus and arsenic are also determined by flask combustion in samples of $30-70 \mu \mathrm{g}$ and are measured by titrimetry or spectrophotometry of molybdenum blue ${ }^{22}$. The combustion procedure employed for all these determinations is shown in Figure 9.

Furthermore Tölg and colleagues have used ultramicro flask determination methods for the determination of sulphur and selenium ${ }^{23}, 24$ (Figure 10). After combustion, the flask is attached to a distillation apparatus, and then 


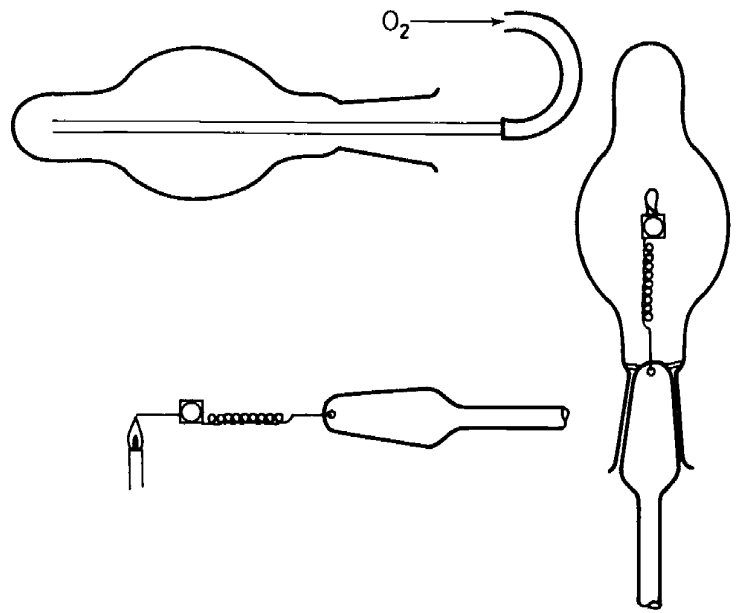

Figure 9. Ultramicro flask combustion method according to Belcher ${ }^{20}$. The sample is weighed out, wrapped in a film of polyethylene, provided with a thread of linen as a fuse and attached to the support. Oxygen is blown into the flask. The fuse is lit and the sample with the stopper is introduced into the flask. The sample is burned quickly and the combustion products are absorbed in the liquid with which the interior of the flask has been moistened.

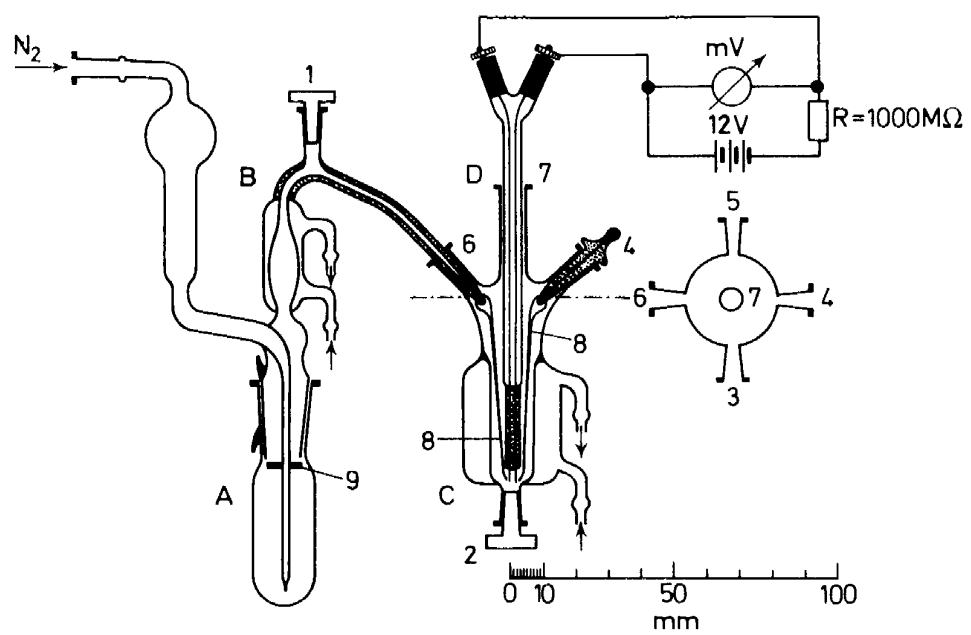

Figure 10. Determination of selenium according to Tölg $e$ al. ${ }^{24}$. The sample is burned by flask combustion in flask A, in a similar way to that described in Figure 9. The flask is attached to the distillation apparatus B. The combustion products are reduced and distilled over into the absorption and titration vessel $\mathrm{C}$, where they are titrated. $\mathrm{D}=$ electrodes. 


\section{W. J. KIRSTEN}

hydrogen sulphide and hydrogen selenide are distilled off and titrated with silver nitrate.

In order to avoid the need for wrapping material, fuses, etc., which might introduce blank risks, we designed two hot-flask combustion methods. In the first one, Figure $11^{25}$, the combustion flask is washed after combustion and used in a similar way as in the flask methods described above. We have used this method for the determination of chlorine, bromine and iodine.
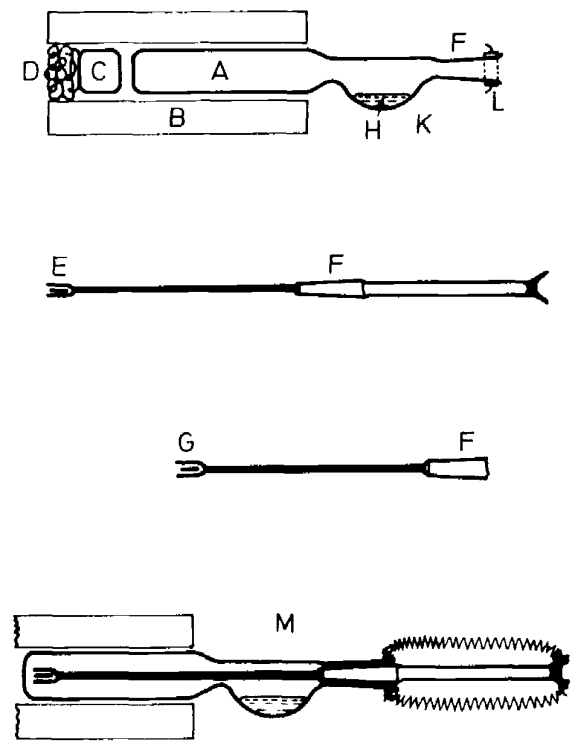

Figure 11. Hot-flask combustion method ${ }^{25} . \mathrm{B}=$ Combustion furnace; $\mathrm{A}=$ quartz flask; $H=$ absorption liquid; $F=$ ground joint with horns $L ; E=$ sample in platinum boat in quartz cup on top of quartz rod. Oxygen is led into the hot flask and the sample is introduced. Joint $\mathrm{F}$ is immediately tightened as seen in inset $\mathrm{M}$ and furnace and flask are tilted, so that the absorption solution covers the joint F. After the combustion the flask is taken out of the furnace and allowed to cool. Titrations or other measurements can then be made in the flask. $\mathrm{C}=$ filling body in furnace; $\mathrm{D}=$ asbestos.

Fernandopulle and Macdonald ${ }^{26}$ have applied it to the determination of fluorine, and Christopher and Fennell ${ }^{27}$ to the determination of phosphorus.

In order to simplify operations, the diffusive hot-flask method was designed (Figure 12) ${ }^{28}$. In this method the combustion products diffuse from the combustion chamber into a small absorption vessel, which is detached, and in which the combustion products are titrated. With this procedure, the complete desorption of the halides from the walls of the flask is very important. $1 \mu \mathrm{l}$ of orthophosphoric acid is therefore added to each sample before combustion. It decomposes alkali halides and prevents their adsorption to the walls of the quartz vessel.

Compared with the decomposition methods in a gas-flow, the flask methods have the advantage of requiring a relatively simple apparatus and very small amounts of reagents for every analysis. This diminishes the risk 


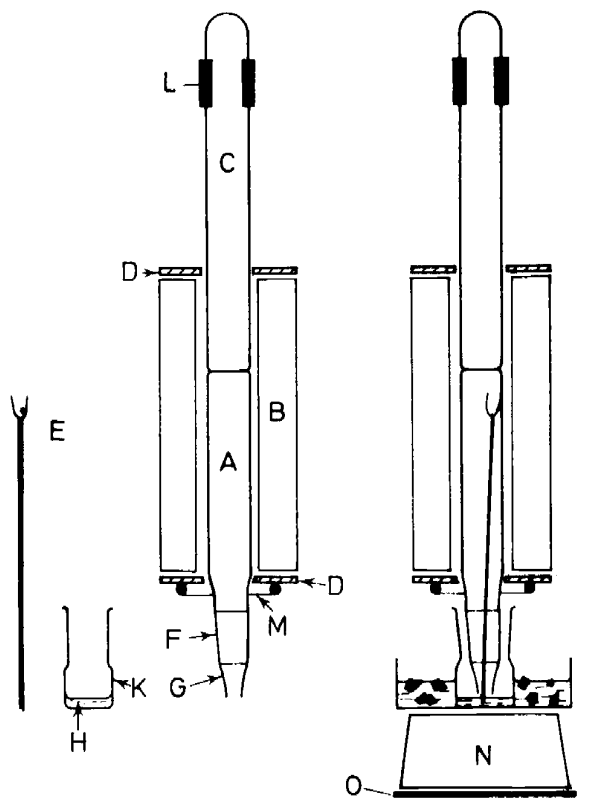

Figure 12. Hot-flask combustion-diffusive absorption method ${ }^{28}$. Rod with sample E, which has been moistened with $1 \mu \mathrm{l}$ of phosphoric acid, is placed into vessel $\mathrm{K}$ with absorption liquid $\mathrm{H}$ and introduced into the hot flask $\mathrm{A}$ where the sample is burned. Combustion products diffuse down into absorption vessel. The vessel is detached, and the analyte is titrated in it.

of blanks and contamination from reagents. On the other hand, there is some risk of contamination of vessels and apparatus during handling prior to combustion and between the combustion and the measurement, which is quite considerable. This is most important in the determination of halogen: hydrochloric acid and other chlorides are quite common contaminants of the laboratory atmosphere. This risk of contamination can be diminished by the use of self-rinsing Grunbaum pipettes, by a suitable treatment of adsorption vessels. When vessels are cleaned with sulphuric acid, washed with redistilled water and dried, active spots are covered with $\mathrm{SO}_{4}^{2-}$ ions, which prevent adsorption of halide. If necessary glove-boxes must be used. In the apparatus with flowing gas, the boat with the sample is introduced against a sweeping gas-flow, which prevents the entrance of impurities, and the whole measurement can be carried out under the protection of this gas. The risk of irreproducible blank is thereby greatly reduced.

\section{Phosphorus, nitrogen}

\section{WET COMBUSTION}

Some elements, such as phosphorus, are most conveniently determined after decomposition of the sample by wet combustion ${ }^{27}$. Most common compounds can be decomposed in open tubes. The orthophosphate formed can be measured spectrophotometrically after reaction with molybdate to 


\section{W. J. KIRSTEN}

molybdophosphoric acid, at $308 \mathrm{~nm}$, or after reduction of the molybdophosphoric acid to molybdenum blue, at $725 \mathrm{~nm}$. Interference from silica and other substances, which form similar complexes, is eliminated by extraction of the molybdophosphoric acid with butyl acetate or amyl acetate ${ }^{29,30}$. The latter has a very low solubility in water, thus eliminating the need for an exhaustive extraction. An accurately measured volume of the solvent is added to the water phase. After agitation and separation of the phases the light absorption can be measured immediately in an aliquot of the organic phase. Molecular absorption of the yellow colour is 25000 , of the blue colour about 23000 . A layout of a combustion arrangement is shown in Figure $13^{31}$. Volatile samples, and some fluorine-containing substances which are difficult to decompose, can be decomposed in sealed tubes ${ }^{27,32,33}$. An apparatus for such a decomposition is shown in Figure 14.

Hashizume and Sasaki ${ }^{34}$ have described an ultramicro method, in which the orthophosphoric acid obtained in the digestion is silylated and determined
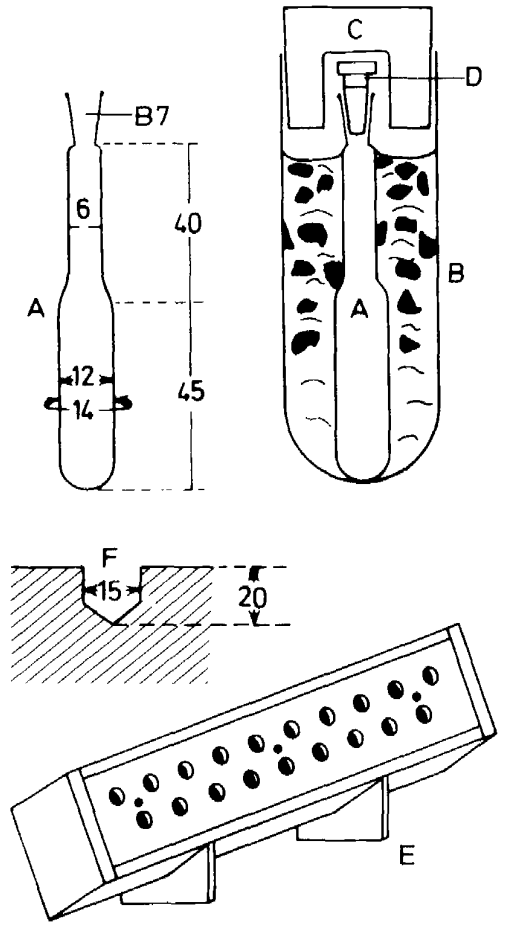

Figure 13. Equipment for digestion and extraction in phosphorus determination ${ }^{31}$. $\mathrm{A}=$ digestion tube of borosilicate glass; $\mathbf{B}=$ centrifuge tube of polyethylene with digestion tube placed in ice water; $\mathrm{C}=$ rubber stopper with bore to hold digestion tube; $\mathrm{D}=$ stopper of polyethylene; $\mathrm{E}=$ electrically heated block of stainless steel with bores for digestion tubes, kept at $250^{\circ} \mathrm{C}$, available from Nicroma, Tulegatan 19, Stockholm, Sweden. Small holes are for thermometers. $\mathrm{F}=$ bore in steel block.

The sample is digested in a mixture of nitric, sulphuric and perchloric acids until only sulphuric acid remains. Water, sodium molybdate, and a measured volume of amyl acetate are added. Molybdophosphoric acid is extracted. The tube is cooled and centrifuged and the colour is measured in an aliquot of organic phase. 

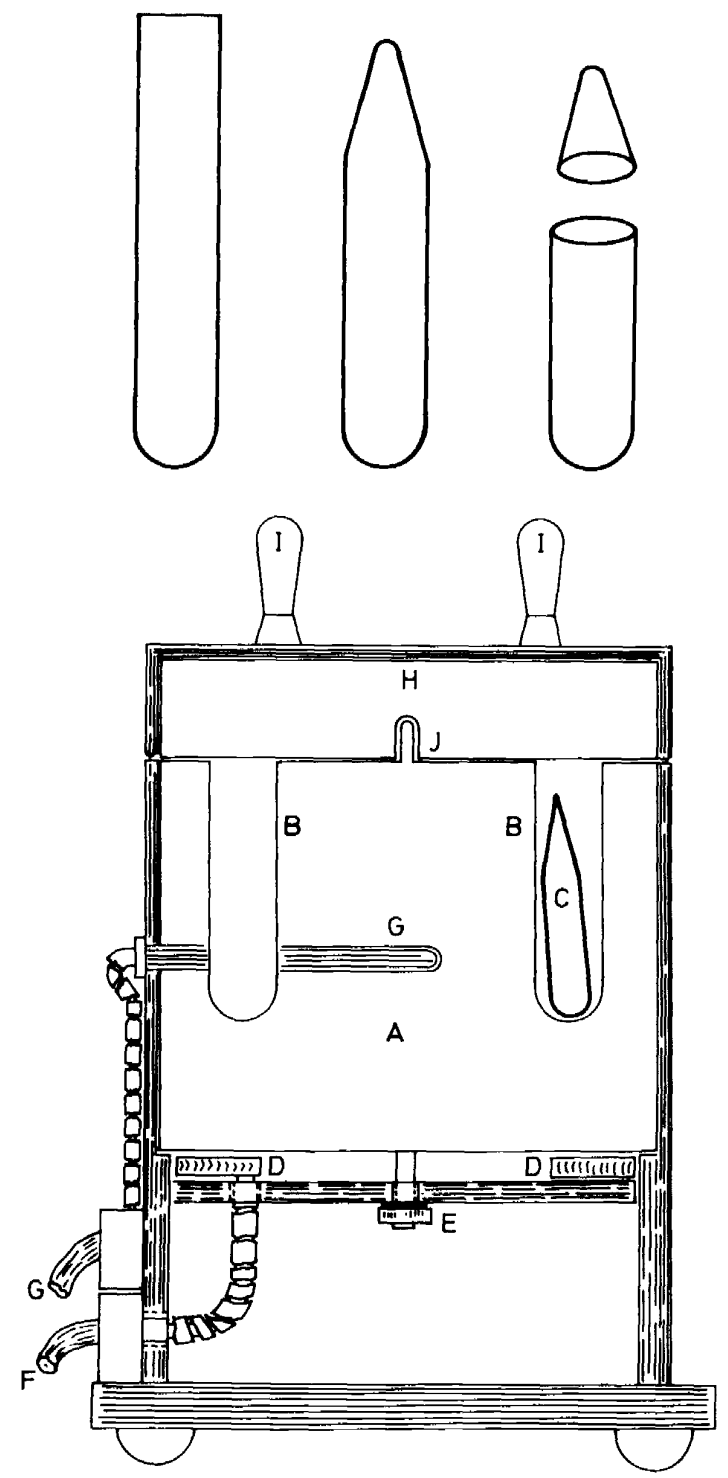

Figure 14. Sealed-tube digestion vessels and thermostatically controlled heating block ${ }^{37}$. $\mathrm{A}=$ Dural aluminium block $; \mathbf{B}=$ cavities to accommodate 10 digestion tubes $\mathrm{C} ; \mathrm{D}=$ heating element; $\mathrm{E}=$ steel clamping plate; $\mathrm{H}=$ Dural lid with hard asbestos handle $\mathrm{I}$; and $\mathrm{J}=$ centring pin for lid. 


\section{W. J. KIRSTEN}

by gas chromatography. Recently, Matthews, et al. ${ }^{35}$ described the determination of phosphate by a modification of this method, using a phosphorusselective flame photometric detector. A series of runs is shown in Figure 15. Thus, if the digestion can be carried out with sufficiently pure reagents, vessels, and instruments, good measuring methods exist for the phosphate formed!

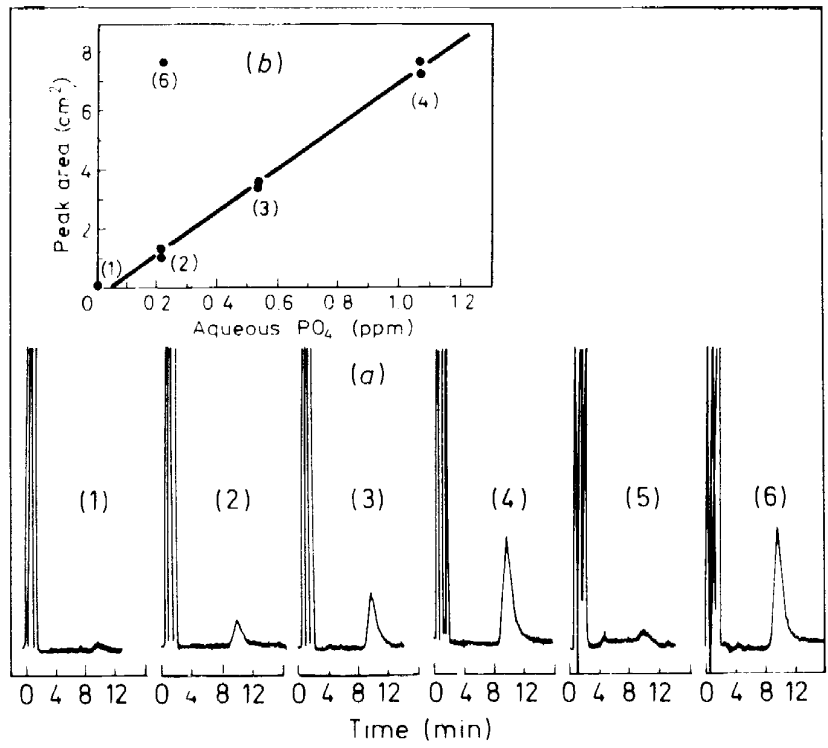

Figure 15. (a) Chromatograms of extracted, derivatized phosphate ${ }^{35}$. (b) Calibration curves obtained from (a). (1) $1 \mu \mathrm{l}$ blank; (2) $1 \mu \mathrm{l} 0.21 \mathrm{ppm} \mathrm{PO}_{4}, 0.068 \mathrm{ng} \mathrm{P}$; (3) $1 \mu \mathrm{l} 0.53 \mathrm{ppm} \mathrm{PO}, 0.17 \mathrm{ng}$ $\mathrm{P}$; (4) $1 \mu \mathrm{l} 1.06$ ppm $\mathrm{PO}_{4}, 0.35 \mathrm{ng} \mathrm{P}$; (5) $5 \mu$ l blank; (6) $5 \mu \mathrm{l} 0.21 \mathrm{ppm} \mathrm{PO}_{4}, 0.34 \mathrm{ng} \mathrm{P}$.

In the wet combustion of nitrogen a digestion temperature somewhat above the boiling point of sulphuric acid is desirable, in order to obtain a complete decomposition of refractory substances. Potassium sulphate is therefore added to raise the boiling point of the solution. When the solution is heated to boiling, part of the sulphuric acid will reflux on the walls of the vessel. In macroanalysis this part is small compared with the bulk of the solution and has little influence upon its temperature, whereas in ultramicroanalysis the refluxing liquid can be a considerable part of the total volume. This causes an increase of the concentration of potassium in the solution, and thus an increase in temperature. Temperature, however, is verry critical and at higher temperatures the ammonium formed is decomposed $^{36}$. Therefore, in order to obtain a safe decomposition at a wellcontrolled temperature, the wet combustion must be carried out in sealed tubes in a well-thermostated apparatus, as shown in Figure 15. Belcher and his school ${ }^{37}$ have also worked out detailed procedures for the determination of nitrogen in different classes of compounds, which cannot be decomposed by simple Kjeldahl digestion. 


\section{QUANTIFICATION OF THE SAMPLE}

As a consequence of the work of analysts and physicists in recent decades, the decomposition methods and measuring methods for ultramicroanalysis function quite well. Beautiful, stable and highly accurate and sensitive balances have been designed. Thus even the weighing causes no trouble, if the sample is stable, non-volatile and non-hygroscopic.

At present, there is no satisfactory method for the quantification of volatile substances and no method at all for mixtures of volatile substances.

When a sample is hygroscopic it must be weighed in a closed vessel. Such vessels are too heavy for really accurate weighing of ultramicro samples. Provided that enough substance is available a correct weighing can be obtained in the following manner. Dry at least $300 \mu \mathrm{g}$ of the sample to constant weight in a small drying vessel ${ }^{38}$. Allow the substance to take up moisture again to constant weight in the laboratory atmosphere. Weigh out samples of the humid substance for the analyses and correct the results for the moisture content. When the sample is deliquescent, dissolve the dried substance, pipette out aliquots and evaporate the solvent before the determination. These methods work well in the determination of carbon and of

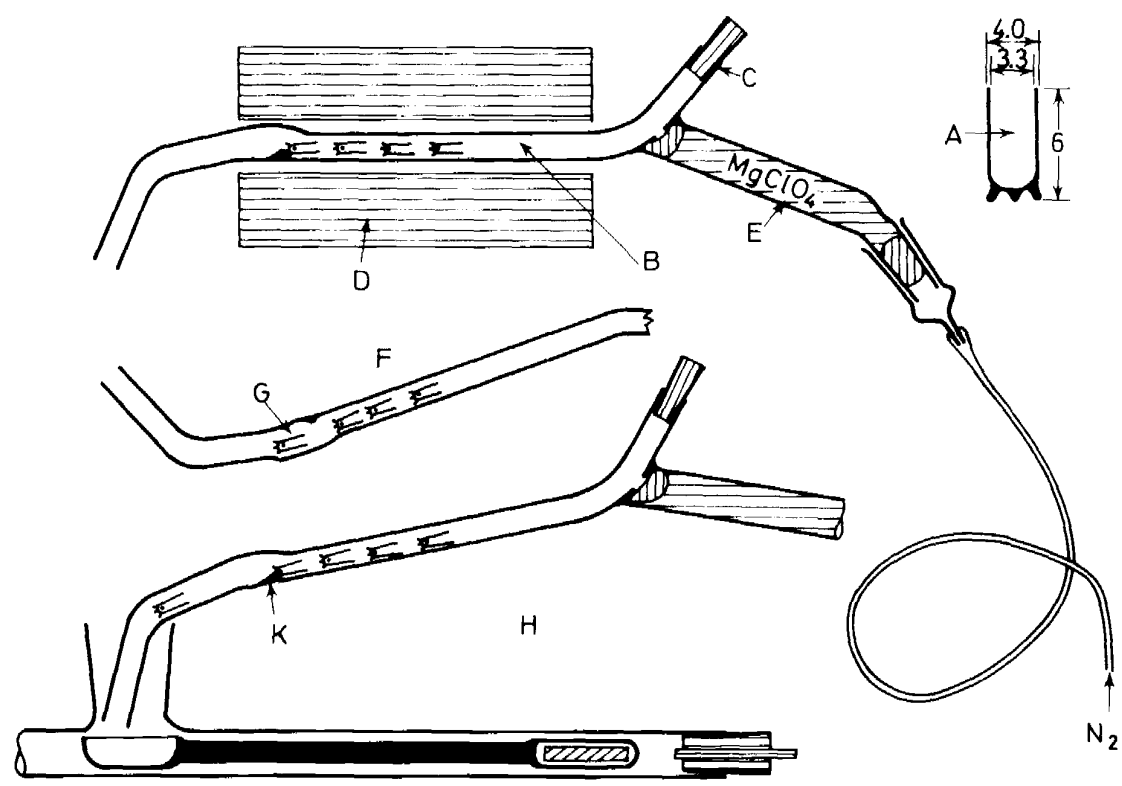

Figure 16. Introduction device for hygroscopic samples. After determination of the moisture content of the substance a sample of it is weighed out in the thin-walled quartz vessel A, weight $100 \mathrm{mg}$. The sample is allowed to slide into the pyrex tube B through opening $\mathrm{C}$, which is closed with a stopper of silicone rubber. Tube $B$ is then placed into the split-type furnace $D$, which is kept at the appropriate drying temperature. The sample is now dried in the flow of nitrogen, which passes through the drying tube with magnesium perchlorate $E$ into tube $B$. After the drying, the device is taken out of the furnace and turned upside down as shown in inset $F$. The first sample slides down into the widened part $G$ of tube $B$. The tube is now turned back and introduced into the opening of the combustion apparatus as shown in inset $H$. The sample container slides down into the combustion tube. Further samples are held back by the shoulder K. 


\section{W. J. KIRSTEN}

most other elements. Interference occurs in some cases in the determination of hydrogen, and the methods cannot be used simply in the determination of oxgen.

When the samples are introduced into the apparatus for the determination of carbon, hydrogen and nitrogen, and also of oxygen, they are swept free from air by a countercurrent of dry gas. This sweeps out some of the humidity from the sample, and its humidity content is then no longer known and cannot be corrected for accurately. Water contains 89 per cent of oxygen. The oxygen results will, therefore, be quite erroneous. The trouble can be overcome by adopting the arrangement shown in Figure 16.

Another way to solve the problem of quantification is the simultaneous determination of several elements in one sample without weighing. The problem is already partially solved by the determination method for carbon, hydrogen and nitrogen, as described above. Ashes can be determined in the same operation by weighing the residue in the boat. Recently, Horton, Shults and Meyer ${ }^{16}$ described an attempt to elaborate a method for the simultaneous determination of nitrogen, phosphorus, sulphur and carbon, using element-sensitive gas chromatographic detectors after pyrolytic hydrogenation. One run with each method would give all ratios between $\mathrm{C}, \mathrm{H}, \mathrm{N}, \mathrm{S}, \mathrm{P}$ and ash. Only the oxygen, the old child of sorrow is lacking. Theoretically, there is no reason why oxygen could not be tackled by the described hydrogenation method. Maybe one day we shall arrive at a complete elemental analysis, including determination of ashes, without a weighing of the sample.

\section{REFERENCES}

1 R. Belcher, Submicro methods of organic analysis, p. 38, Elsevier, London (1966).

2 R. Belcher, G. Dryhurst, A. M. G. Macdonald, J. R. Majer and G. J. Roberts, Anal. Chim. Acta, 43, 441 (1968).

3 W. Walisch. Chem. Ber.. 94, 2314 (1961); Trans. N.Y. Acad. Sci., 25, 694, (1963).

3a W. Kirsten, Microchem. J., 16, 610(1971).

4 W. Walisch and W. Marks, Mikrochim. Acta, 1051 (1967).

5 W. J. Kirsten, Proc. 1961 , int. symp. microchem. techn., p. 479, Interscience, New York (1962).

6 T. D. Rees, A. B. Gyllenspetz and A. C. Docherty, Analyst, 96, 201 (1971).

7 W. J. Kirsten and V. Patel, Microchem. $J$, in the press.

8 G. Tölg, Habilitationsschrift, Mainz 1965, through G. Tölg Chemische Elementaranalysen mit kleinsten Proben, p. 142, Verlag Chemie, Weinheim, West Germany (1968).

9 K. H. Ballschmiter and G. Tölg, Z. Anal. Chem., 203, 20 (1964).

10 G. Tölg, Z. Anal. Chem., 205, 40 (1964).

11 G. Tölg and K. H. Ballschmiter, Microchem. J., 9, 257 (1965).

12 G. Schwab and G. Tölg, Z. Anal. Chem., 205, 29 (1964).

13 W. H. List and G. Tölg, Z. Anal. Chem., 226, 127 (1967).

14 B. Morsches and G. Tölg, Z. Anal. Chem., 200, 20 (1964).

15 F. C. A. Killer, $И$ International symposium on microtechniques, Vol. A. p. 113, Wien (1970).

16 A. D. Horton, W. D. Shults and A. S. Meyer, Anal. Letters, 4, 613 (1971).

17 W. Krijgsman and B. Griepink, VI International symposium on microtechniques, Vol. A. p. 129, Wien (1970).

18 R. Belcher, Submicro methods of organic analysis, p. 62, Elsevier, London (1966).

19 R. Belcher, Submicro methods of organic analysis, p. 55, Elsevier, London (1966).

20 R. Belcher, P. Gouverneur and A. M. G. Macdonald, J. Chem. Soc., 1938 (1962).

21 R. Belcher, A. D. Campell, P. Gouverneur and A. M. G. Macdonald, J. Chem. Soc., 3003 (1962).

22 R. Belcher, Submicro methods of organic analysis, p. 72, Elsevier, London (1966).

23 G. Tölg, Z. Anal. Chem., 194, 20 (1963). 


\section{QUANTITATIVE ORGANIC ULTRAMICRO ELEMENTARY ANALYSIS}

24 R. Engler and G. Tölg, Z. Anal. Chem., 235, 151 (1968).

25 W. J. Kirsten, Microchem. J., 7, 34 (1963).

26 M. E. Fernandopulle and A. M. G. Macdonald, Microchem. J., 11, 41 (1966).

27 A. J. Christopher and T. R. F. W. Fennel, Techn. Report 67115, Royal Aircraft Establishment, Farnborough, Hants, England.

28 W. J. Kirsten, Microchem. J., 12, 177 (1967).

29 C. Wadelin and M. Q. Mellon, Anal. Chem., 25, 1668 (1953).

30 M. A. DeSesa and L. B. Rogers, Anal. Chem., 26, 1381 (1954).

31 W. J. Kirsten, Microchem. J., 12, 307 (1967).

32 W. J. Kirsten and M. E. Carlsson, Microchem. J., 4, 3 (1960).

33 W. J. Kirsten, Microchem. J., 12, 307 (1967).

34 T. Hashizume and Y. Sasaki, Anal. Biochem., 21, 316 (1967).

35 D. R. Matthews, W. D. Shults, M. R. Guerin and J. A. Dean, Anal. Chem., 24, 1487 (1952).

36 B. W. Grunbaum, F. L. Schaffer and P. L. Kirk, Anal. Chem., 24, 1487 (1952).

37 R. Belcher, Submicro methods of organic analysis, p. 22, Elsevier, London (1966).

38 W. J. Kirsten, Mikrochim. Acta, 105 (1966). 